\title{
Carbon-black-doped Polyimide-modified Glassy Carbon Electrode for Sensitive Nonenzymatic Amperometric Determination of Hydrogen Peroxide
}

\author{
Yue Wang, ${ }^{1}$ Lin Chen, ${ }^{1,2}$ Yan Zhang, ${ }^{1}$ Qingnan Wang, ${ }^{1}$ \\ Ruidan Ma, ${ }^{1}$ Yasushi Hasebe, ${ }^{3 *}$ Zhiqiang Zhang, ${ }^{1}$ and Zhizhi $\mathrm{Hu}^{1 * *}$ \\ ${ }^{1}$ School of Chemical Engineering, University of Science and Technology Liaoning, \\ 185 Qianshan Middle Road, High-tech zone, Anshan, Liaoning 114051, China \\ ${ }^{2}$ Department of Chemistry and Environmental Engineering, Yingkou Institute of Technology, \\ Yingkou, Liaoning 115014, China \\ ${ }^{3}$ Department of Life Science and Green Chemistry, Faculty of Engineering, \\ Saitama Institute of Technology, 1690 Fusaiji, Fukaya, Saitama 369-0293, Japan
}

(Received November 2, 2018; accepted December 3, 2018)

Keywords: polyimide, carbon black, hydrogen peroxide, sensor

In this study, a novel nonenzymatic sensor for the determination of hydrogen peroxide $\left(\mathrm{H}_{2} \mathrm{O}_{2}\right)$ was developed. The direct electrocatalytic oxidation of $\mathrm{H}_{2} \mathrm{O}_{2}$ in an aqueous medium at a carbon-black (CB)-doped self-made polyimide (PI)-modified glassy carbon electrode (GCE) was investigated. The fabrication of this electrode is simple and reproducible. The filmlike surface was prepared by directly mixing the $\mathrm{CB}$ and PI solution. Under optimized conditions, the linear range of $\mathrm{H}_{2} \mathrm{O}_{2}$ is from 6 to $10000 \mu \mathrm{M}$ with the detection limit of $1 \mu \mathrm{M}$. The electrode exhibited high stability, excellent sensitivity, stable reproducibility, and fast response time (less than $5 \mathrm{~s}$ ). The results show that PI can be used as a reliable and long-life sensor for hydrogen peroxide detection, exhibiting a new application for the PI.

\section{Introduction}

Hydrogen peroxide $\left(\mathrm{H}_{2} \mathrm{O}_{2}\right)$ is present in nature, particularly in waterways and various life systems. ${ }^{(1)}$ It is an effective, safe, and useful oxidant, and is widely used in various fields because of its good properties. There is much interest in the determination of $\mathrm{H}_{2} \mathrm{O}_{2}$ in analytical science because of the importance of $\mathrm{H}_{2} \mathrm{O}_{2}$ in different fields, such as food, industrial, clinical, and environmental analyses. ${ }^{(2)}$ Many analytical methods have been proposed for the detection of $\mathrm{H}_{2} \mathrm{O}_{2}$ such as chromatography, ${ }^{(3)}$ chemiluminescence, ${ }^{(4)}$ and electrochemistry. ${ }^{(5-7)}$ Electrochemistry has proved to be effective for $\mathrm{H}_{2} \mathrm{O}_{2}$ determination. Redox proteins including horseradish peroxidase, ${ }^{(8,9)}$ myoglobin, ${ }^{(10)}$ hemoglobin, ${ }^{(11)}$ and cytochrome $\mathrm{c}^{(12)}$ have been used for the fabrication of $\mathrm{H}_{2} \mathrm{O}_{2}$ biosensors. However, enzymatic sensors usually suffer from the effects of temperature, $\mathrm{pH}$, and toxic compounds because of the intrinsic nature of enzymes. ${ }^{(13)}$ In order to overcome these disadvantages, nonenzymatic sensors were developed

\footnotetext{
*Corresponding author: e-mail: hasebe@sit.ac.jp

** Corresponding author: e-mail: huzhizhi@163.com

https://doi.org/10.18494/SAM.2019.2179
} 
to detect glucose and hydrogen peroxide. ${ }^{(14,15)}$ Numerous functional materials were used for the nonenzymatic sensing of $\mathrm{H}_{2} \mathrm{O}_{2}$, including nanomaterials, ${ }^{(16-18)}$ ionic liquids, ${ }^{(19)}$ ceramics, ${ }^{(20)}$ polymers, ${ }^{(21)}$ organic dyes, ${ }^{(22,23)}$ and minerals. ${ }^{(24)}$

Flexible electronics have been developed extensively in recent years. Many flexible materials have been used in flexible sensors. ${ }^{(25)}$ Polyimide (PI) is a type of polymer material with low crystallinity and an amorphous structure. Owing to its excellent characteristics such as rigid chain structure, excellent thermal stability, radiation resistance, dimensional stability, and mechanical and electrical properties, it has been widely used as an electric and electronic material in automobiles, aerospace, flexible circuit boards, liquid crystal displays, adhesives, coatings, and other fields. ${ }^{(26,27)}$ PIs with unique properties have been developed because a numerous number of studies have been performed on the relationships between the structure and properties of PIs. ${ }^{(28)}$ However, their excellent insulation performance also limits their application in the field of electronics. Therefore, a variety of methods to improve the conductive properties of PI will make the application more attractive in the electrochemical field.

In this study, we report a novel sensor that consists of a carbon-black (CB)-doped self-made PI-modified GCE (CB/PI-GCE). The CB/PI-GCE sensor was used for the detection of $\mathrm{H}_{2} \mathrm{O}_{2}$ in an aqueous electrolyte. The main purpose of this study was to further explore the analytical applications of PI electrodes, with a focus on developing a rapid, sensitive, inexpensive, and long-life sensor for the determination of $\mathrm{H}_{2} \mathrm{O}_{2}$, which is a biologically important compound. It has been found that under optimum conditions, the $\mathrm{CB} / \mathrm{PI}-\mathrm{GCE}$ sensor showed good sensitivity, rapid response time, and excellent stability for the detection of $\mathrm{H}_{2} \mathrm{O}_{2}$. This result will be used to fabricate precise and reliable amperometric sensors on a PI-based electrode.

\section{Materials and Methods}

\subsection{Reagents and materials}

4,4'-(Hexafluoroisopropylidene)diphthalic dianhydride (6FDA) was purchased from ChinaTech (Tianjin) Chemical Co., Ltd., which was recrystallized from acetic anhydride and vacuum-dried before use. 9,9'-bis(4-hydroxy phenyl) fluorene (BHF) was purchased from Sinosteel Anshan Research Institute of Thermo-energy Co., Ltd., China. Graphite, N,N'dimethylacetamide (DMAc), Pd/C (10\%), hydrazine hydrate, acetone, nitric acid, ethanol, acetic anhydride, pyridine, glucose (Glu), fructose (Fru), sucrose (SC), sodium hydroxide ( $\mathrm{NaOH}$ ), phosphoric acid, glacial acetic acid, boric acid, and $\mathrm{H}_{2} \mathrm{O}_{2}$ were purchased from Sinopharm Chemical Reagent Co., Ltd., China. DMAc was dried using anhydrous molecular sieves before use. Carbon black was obtained from CABOT Corporation and used as received. A $0.1 \mathrm{M}$ Britton-Robinson buffer (BR, prepared by mixing phosphoric acid, glacial acetic acid, and boric acid) was used to prepare an electrolyte for the acidic solution. The neutral and alkaline solutions were adjusted by blending the mixed acid and $0.1 \mathrm{M} \mathrm{NaOH}$. All other chemicals were of analytical grade and were used without further purification. 


\subsection{Apparatus}

${ }^{1} \mathrm{H}-\mathrm{NMR}$ spectra were recorded on a Bruker Advance-AV 500 MHZ (Germany) instrument with deuterated dimethyl sulfoxide (DMSO-d6) as the solvent. The FT-IR spectra of monomers and polymer powders were measured on a Nicolet iS10 (USA) instrument. The average scanning frequency of the instrument was 16 times. The X-ray diffraction (XRD) pattern was taken from 5 to $60^{\circ}$ ( $2 \theta$ value) with $\mathrm{Cu}-\mathrm{K} \alpha$ radiation $(\lambda=1.541 \AA)$ using an X'Pert Powder X-ray diffractometer (PANalytical, Netherlands).

The morphologies of the modified electrode surfaces were observed by field emission scanning electron microscopy (FE-SEM, LIGMA-HD, ZEISS, Germany) and atomic force microscopy (AFM, Being Nano-instruments CSPM-5500, BenYuan, China). Electrochemical measurements were performed with a CHI 750D workstation (Shanghai Chenhua, China). A conventional three-electrode system with a PI electrode as the working electrode, a thin Pt wire as the counter electrode, and $\mathrm{Ag} / \mathrm{AgCl}$ (sat. $\mathrm{KCl}$ ) as the reference electrode was used in this study. All measurements were performed in air at a room temperature of approximately $20^{\circ} \mathrm{C}$.

\subsection{Synthesis of intermediates and PI}

The synthesis methods of intermediates and PI are similar to those described in our previous reported paper. ${ }^{(29)}$ Briefly, concentrated nitric acid $(5.0 \mathrm{~g})$ was dropped into $20 \mathrm{~mL}$ of acetone, which contains $5.0 \mathrm{~g}$ of BHF. The mixture was reacted between 0 and $3{ }^{\circ} \mathrm{C}$ overnight to obtain the dinitro compound, which is abbreviated as BNHF. Then, BNHF (13.2 g), 10\% Pd/C (0.5 g), and ethanol $(60 \mathrm{~mL})$ were mixed in a three-neck flask. Hydrazine hydrate $(60 \mathrm{~mL})$ was then dropped into the mixture within $1 \mathrm{~h}$ and reacted at $80{ }^{\circ} \mathrm{C}$ for $24 \mathrm{~h}$ to obtain a diamine monomer (BAHF). The BAHF was filtered and washed with ethanol after removing the catalyst $(\mathrm{Pd} / \mathrm{C})$. Details of the reaction procedure are shown in Fig. A1.

The typical procedure for PI synthesis is a two-step chemical imidization method (Fig. A2). $0.05 \mathrm{~mol}$ of BAHF is put into $100 \mathrm{~mL}$ of DMAc in a three-neck flask. After it fully dissolved in DMAc at room temperature, 6FDA is added into the mixture and continuously stirred for $12 \mathrm{~h}$ under a nitrogen atmosphere to obtain a viscous poly(amic acid) solution. Chemical imidization is carried out in the polyamic acid by adding a mixture of acetic anhydride and pyridine, and reacting for $24 \mathrm{~h}$. Finally, the PI solution is poured into a methanol solvent. Then, the PI is collected by filtration and vacuum-dried at $120^{\circ} \mathrm{C}$ for $12 \mathrm{~h}$.

\subsection{Fabrication of CB/PI-GCE sensor}

PI (30 mg) is diluted in DMAc solvent $(0.57 \mathrm{~g})$ and sonicated for $30 \mathrm{~min}$ to obtain a homogeneous solution. The $\mathrm{CB}$ dispersion is prepared by putting $5 \mathrm{mg}$ of $\mathrm{CB}$ into $0.5 \mathrm{~mL}$ of DMAc and sonicated for $30 \mathrm{~min}$. The PI solution is mixed with the CB dispersion and sonicated for $30 \mathrm{~min}$, which is donated as the CB/PI solution. The glassy carbon electrode (GCE, $3.0 \mathrm{~mm}$ in diameter) is polished successively with $1.0,0.3$, and $0.05 \mathrm{~mm} \alpha$-alumina slurries to obtain a shiny surface. The cleaned electrode is rinsed and sonicated with distilled water and ethanol to 
remove any adhering alumina. Then, the $\mathrm{CB} / \mathrm{PI}$ solution is dropped onto the GCE surface for $24 \mathrm{~h}$ to prepare the $\mathrm{H}_{2} \mathrm{O}_{2}$ sensor. The CB/PI-GCE sensor for the analysis of $\mathrm{H}_{2} \mathrm{O}_{2}$ followed by the electrochemical detection process is shown in Fig. 1.

\section{Results and Discussion}

\subsection{Structure characterization of monomers and PI}

All PI precursor chemical structures were confirmed by ${ }^{1} \mathrm{H}-\mathrm{NMR}$ and FT-IR spectroscopy (data not shown). The structures of BNHF and BAHF were also confirmed by FT-IR and ${ }^{1} \mathrm{H}-\mathrm{NMR}$ spectroscopy. Figure A3 indicates the FT-IR spectra of the dinitro compound (BNHF) and the diamine monomer (BAHF). The absorption bands at 1577 and $1350 \mathrm{~cm}^{-1}$ of dinitro group peaks disappeared in the BAHF spectrum. Moreover, the characteristic absorption peaks of amine groups appeared in 3436 and $3376 \mathrm{~cm}^{-1}$, indicating that BNHF was successfully reduced to BAHF. Figures A4 and A5 show the ${ }^{1} \mathrm{H}-\mathrm{NMR}$ spectra of BNHF and BAHF, respectively.

The chemical structure of PI was also identified by FT-IR measurement. As shown in Fig. A6, the synthesized polymer exhibits a typical imide ring absorbance at approximately 1783 , 1716,1372 , and $722 \mathrm{~cm}^{-1}$ toward the following groups (symmetric $\mathrm{C}=\mathrm{O}$, asymmetric $\mathrm{C}=\mathrm{O}, \mathrm{C}-\mathrm{N}$ stretching, and ring deformation). A strong and broad absorbance at $3402 \mathrm{~cm}^{-1}$ was ascribed to the phenolic hydroxyl groups in the PI. ${ }^{(30)}$ The morphological examination of the PI was also examined by XRD. As shown in Fig. A7, a broad peak was observed, which revealed the characteristics of amorphous PI. The intersegmental distance of the polymer was 0.504 $\mathrm{nm}\left(2 \theta=17.58^{\circ}\right)$. It is attributable to the existence of rigid fluorene, hydroxyl, and six fluoro groups, which increases the free volume of molecular chains and the unfavorable formation of crystalline structures.

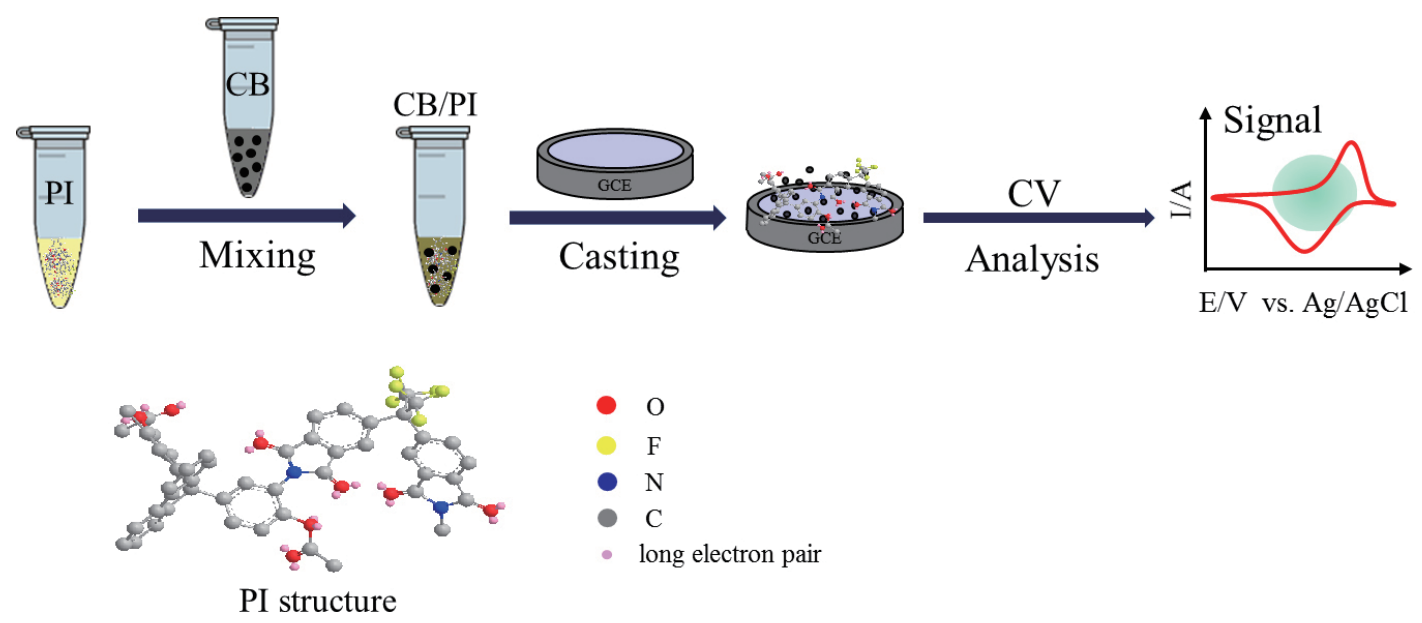

Fig. 1. (Color online) Schematic illustration of CB/PI-GCE sensor for electrochemical determination of $\mathrm{H}_{2} \mathrm{O}_{2}$. 


\subsection{Characteristics of PI-modified electrode}

Field emission scanning electron microscopy (FE-SEM) was used to investigate the morphologies of the PI-modified electrode [Fig. 2(A)] and CB/PI-modified electrode [Fig. 2(B)]. It can be seen that there is a relatively high homogeneity in particle size and distributions after doping with CB [Fig. 2(B)] because the free volume of molecular chains gave a large capacity and freedom for the $\mathrm{CB}$. The high uniformity demonstrates that $\mathrm{CB}$ was trapped in the network of PI and distributed homogeneously, which is effective for the high electrocatalysis of $\mathrm{H}_{2} \mathrm{O}_{2}$.

In addition, the AFM images of PI-GCE [Fig. 2(C)] and CB/PI-GCE [Fig. 2(D)] were evaluated. The PI-GCE shows a fibrous structure. After the addition of $\mathrm{CB}$, the surface roughness of CB/PI-GCE decreased. The average roughnesses of PI-GCE and CB/PI-GCE are 137 and $74.2 \mathrm{~nm}$, respectively. The results indicate that CB was dispersed into the PI matrix homogeneously. The hydroxyl-containing PI has strong adhesion, ${ }^{(31)}$ which enhances the stability of the PI-based electrochemical sensor.

\subsection{Electrochemical properties of CB/PI-GCE sensor}

To confirm the electrocatalytic activity of CB/PI-GCE towards $\mathrm{H}_{2} \mathrm{O}_{2}$, we measured CVs in the presence of $\mathrm{H}_{2} \mathrm{O}_{2}$ using four electrodes: (1) CB/PI-GCE, (2) PI-GCE, (3) CB-GCE, and (4) bare-GCE. A large anodic current appeared from +0.3 to $+0.7 \mathrm{~V}$ for CB/PI-GCE. The electrocatalytic activities are small for the other three electrodes. Both CB-GCE and PIGCE failed to give a good response toward $\mathrm{H}_{2} \mathrm{O}_{2}$. PI is very useful as a host matrix for $\mathrm{CB}$ immobilization. The large capacity of PI can enhance the trapped amount of CB. The CVs of the $\mathrm{CB} / \mathrm{PI}-\mathrm{GCE}$ with and without $\mathrm{H}_{2} \mathrm{O}_{2}$ in $0.1 \mathrm{M}$ air-saturated $\mathrm{NaOH}$ solution are shown in Fig.

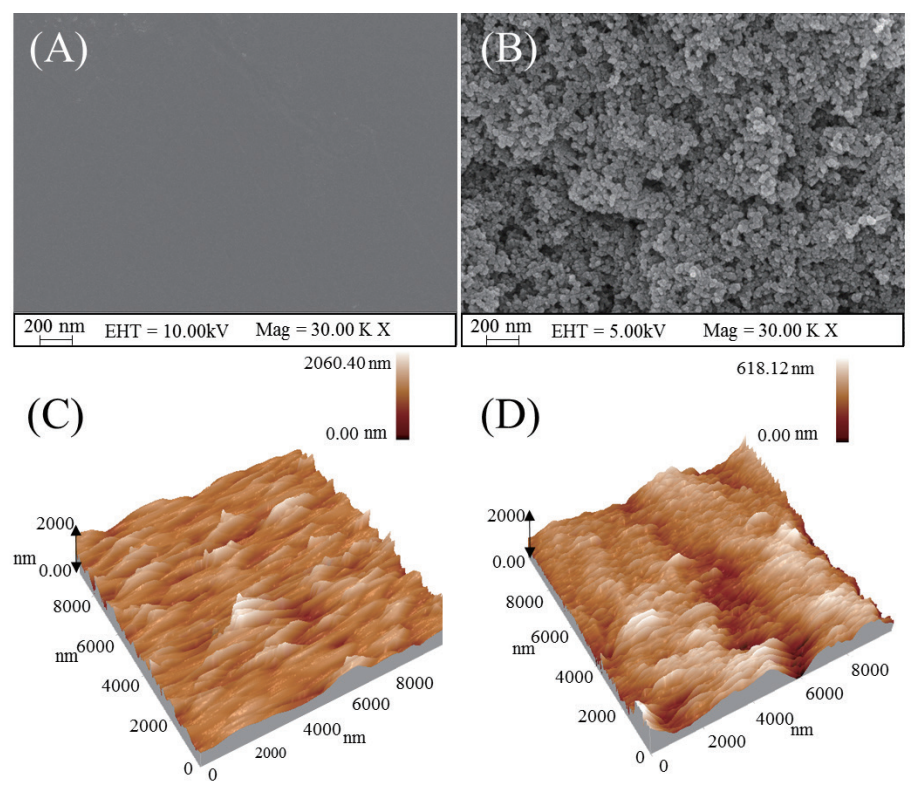

Fig. 2. (Color online) SEM and AFM images of PI/GCE (A, C), and CB/PI-GCE (B, D). 
3(B). The anodic current increased with increasing $\mathrm{H}_{2} \mathrm{O}_{2}$ concentration in the air-saturated electrolyte, indicating that the CB/PI-GCE-based sensor has a wide linear range and good sensitivity for $\mathrm{H}_{2} \mathrm{O}_{2}$.

To identify the optimum conditions of the CB/PI-GCE sensor used for the detection of $\mathrm{H}_{2} \mathrm{O}_{2}$, the CB concentration, applied potential, and $\mathrm{pH}$ dependence of the electrolyte were optimized in aqueous solutions. The effect of electrolyte $\mathrm{pH}$ on the anodic current from $\mathrm{pH} 3$ to 13 was studied and the results are shown in Fig. 4(A). The amperometric response towards $\mathrm{H}_{2} \mathrm{O}_{2}$ increased gradually from $\mathrm{pH} 3$ to 12 , and sharply increased at $\mathrm{pH} 13$. We obtained the maximum anodic current towards $200 \mu \mathrm{M} \mathrm{H}_{2} \mathrm{O}_{2}$ in $0.1 \mathrm{M} \mathrm{NaOH}(\mathrm{pH}$ 13) electrolyte. The results suggest that an alkaline solution is highly effective for obtaining a higher response. However, the operational stability in $\mathrm{pH} 13$ is not good in comparison with the neutral and acidic electrolytes. From these results, the application of the CB/PI-GCE sensor is not restricted to the alkaline solution. This wide $\mathrm{pH}$ range is useful for not only commercial applications, but also future studies in combination with enzymes. The finding on the nonenzymatic sensor is very valuable and encouraging because the alkaline solution is necessary in some cases. ${ }^{(16,32,33)}$
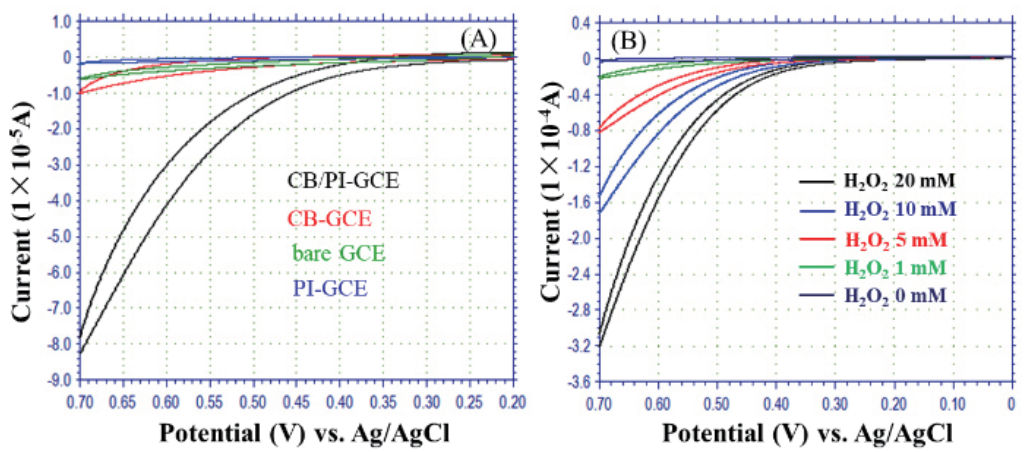

Fig. 3. (Color online) (A) CVs of CB/PI-GCE, CB-GCE, PI-GCE, and bare-GCE in the presence of $5 \mathrm{mM} \mathrm{H}_{2} \mathrm{O}_{2}$. (B) $\mathrm{CVs}$ of $\mathrm{CB} / \mathrm{PI}-\mathrm{GCE}$ at different $\mathrm{H}_{2} \mathrm{O}_{2}$ concentrations $(0-20 \mathrm{mM})$. ([CB] $\left.=30 \mathrm{mg} / \mathrm{mL}, 0.1 \mathrm{M} \mathrm{NaOH}\right)$
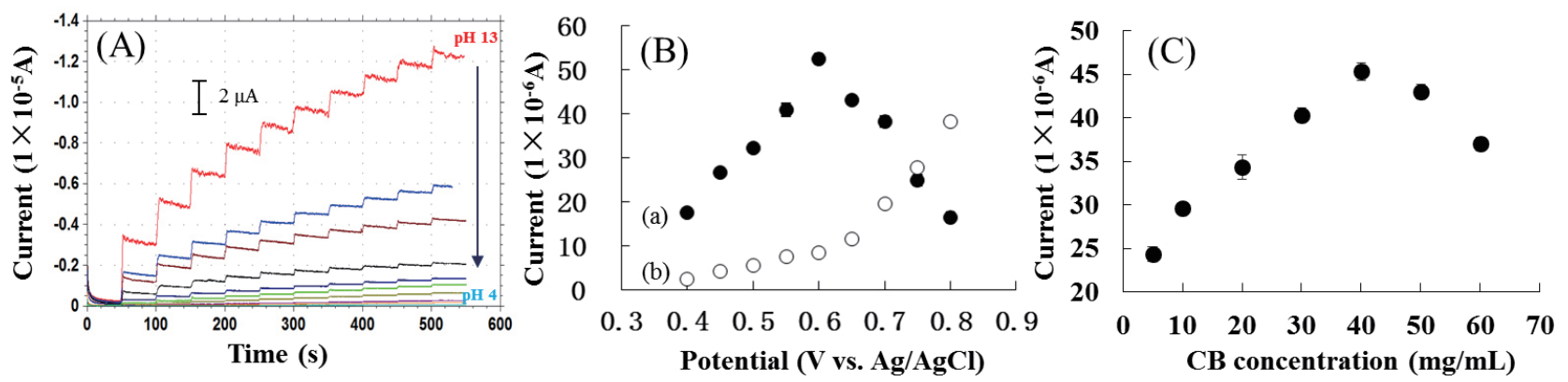

Fig. 4. (Color online) (A) Effect of electrolyte $\mathrm{pH}$ on the anodic current of $200 \mu \mathrm{M} \mathrm{H}_{2} \mathrm{O}_{2}$ in air-saturated $0.1 \mathrm{M}$ BR buffer. (B) Effects of applied potential on the anodic current of (a) $2 \mathrm{mM} \mathrm{H}_{2} \mathrm{O}_{2}$ and (b) background current. (C) Effect of $\mathrm{CB}$ concentration on the anodic current of $2 \mathrm{mM} \mathrm{H}_{2} \mathrm{O}_{2}$. (Current-time response measured at applied potential of $+0.6 \mathrm{~V}$ for $\mathrm{A}, \mathrm{C}$; $[\mathrm{CB}]=30 \mathrm{mg} / \mathrm{mL}$ for $\mathrm{A}, \mathrm{B}$ ) 
The response currents were also measured as a function of applied potential from 0.4 to 0.8 with a step of $0.05 \mathrm{~V}$, and the results are shown in Fig. 4(B). Figure 4(B)(a) shows the difference between the anodic current of $\mathrm{H}_{2} \mathrm{O}_{2}$ and the baseline. The amperometric response of $2 \mathrm{mM}$ $\mathrm{H}_{2} \mathrm{O}_{2}$ increased with increasing potential from 0.4 to $0.6 \mathrm{~V}$. Higher than $+0.6 \mathrm{~V}$, the responses of $\mathrm{H}_{2} \mathrm{O}_{2}$ decreased because the noise level also rises and the drift of the baseline was serious in the high-potential region. Owing to the insulation of PI, the amount of doped conductive compound is extremely important for obtaining high electrochemical activity. To obtain the best performance, the $\mathrm{CB}$ concentration is investigated as shown in Fig. 4(C). The greatest response is observed when $\mathrm{CB}$ is $40 \mathrm{mg} / \mathrm{mL}$. The phenomena can be ascribed to the large surface and capacity of PI.

Figure 5(A) shows a typical current-time plot of the CB/PI-GCE sensor in $0.1 \mathrm{M} \mathrm{NaOH}$ with consecutive step changes in $\mathrm{H}_{2} \mathrm{O}_{2}$ concentrations at the potential of $+0.6 \mathrm{~V}$ (vs $\mathrm{Ag} / \mathrm{AgCl}$ ). The inset shows the enlargement of the lowest concentration $\left(6 \mu \mathrm{M} \mathrm{H}_{2} \mathrm{O}_{2}\right)$. The present sensor shows a fast current response and achieves a steady-state current density within $5 \mathrm{~s}$. The calibration curves of the $\mathrm{H}_{2} \mathrm{O}_{2}$ sensor [Fig. 5(B)] show a linear range of 6-10000 $\mu \mathrm{M}$ and the regression equation $I(\mu \mathrm{A})=0.0249+4.8452 C(\mathrm{mmol} / \mathrm{L})$ with a correlation coefficient of 0.9987 . The limit of detection (LOD) is as low as $1.0 \mu \mathrm{M}(\mathrm{S} / \mathrm{N}=3)$. In comparison with other $\mathrm{H}_{2} \mathrm{O}_{2}-$ based sensor systems shown in Table 1, the characteristics of the present sensor are comparable, especially considering the low cost, high sensitivity, fast response time, and long lifetime. ${ }^{(34-39)}$
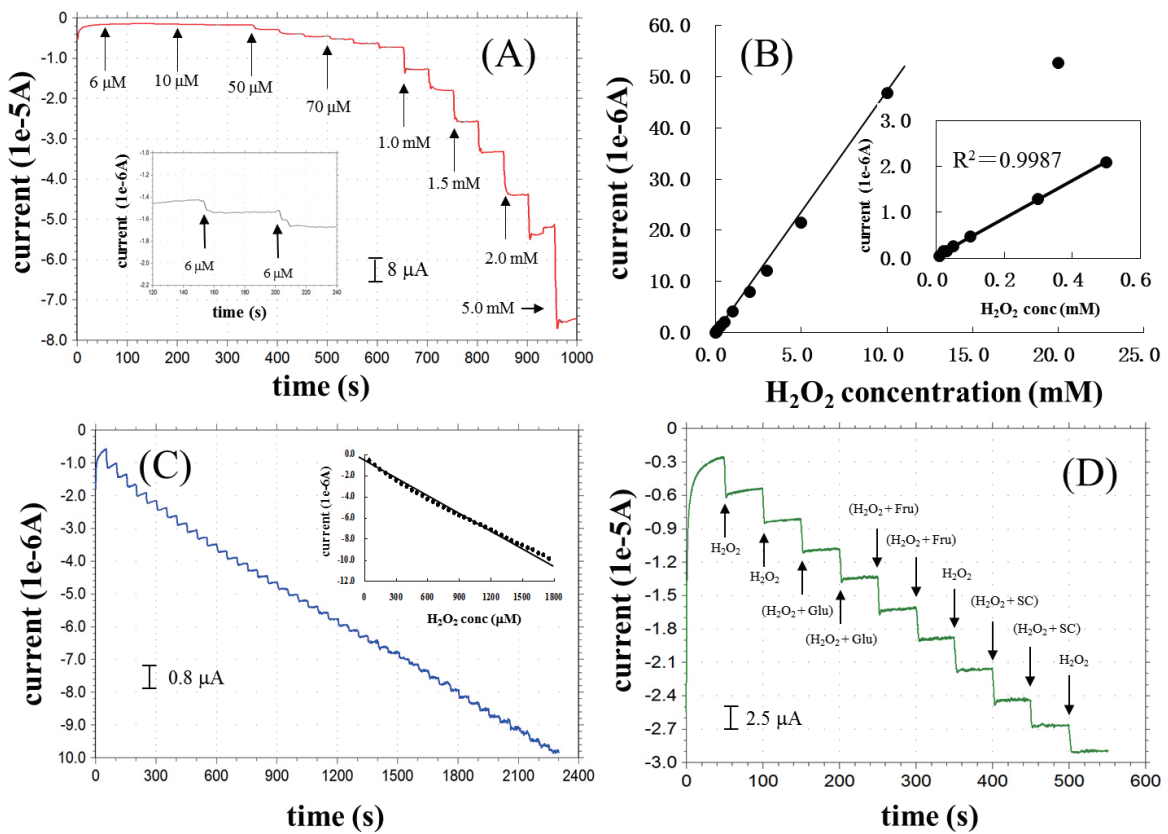

Fig. 5. (Color online) (A) Amperometric responses of CB/PI-GCE sensor for the successive additions of different concentrations of $\mathrm{H}_{2} \mathrm{O}_{2}$. (The inset shows the enlargement of the lowest concentration). (B) Calibration curves of $\mathrm{H}_{2} \mathrm{O}_{2}$ obtained with $\mathrm{CB} / \mathrm{PI}-\mathrm{GCE}$ sensors. The inset shows the lower concentration range of the calibration curves of the sensor. (C) Amperometric response of $50 \mu \mathrm{M} \mathrm{H}_{2} \mathrm{O}_{2}$ on CB/PI-GCE. The inset shows the linear relationship of $\mathrm{H}_{2} \mathrm{O}_{2}$ concentration with current response. (D) Amperometric responses of CB/PI-GCE for the successive addition of $0.2 \mathrm{mM} \mathrm{H}_{2} \mathrm{O}_{2}$, the mixture of $0.2 \mathrm{mM} \mathrm{H}_{2} \mathrm{O}_{2}$, and other interferences. (Current-time response measured in $0.1 \mathrm{M}$ $\mathrm{NaOH}$ at $+0.6 \mathrm{~V}$ vs $\mathrm{Ag} / \mathrm{AgCl},[\mathrm{CB}]=40 \mathrm{mg} / \mathrm{mL}$ for $\mathrm{A}$ to $\mathrm{D})$ 
Table 1

Comparison between sensors investigated in this study and other $\mathrm{H}_{2} \mathrm{O}_{2}$ sensors.

\begin{tabular}{lccc}
\hline Electrode & Linear range $(\mathrm{mmol} / \mathrm{L})$ & $\mathrm{LOD}(\mu \mathrm{mol} / \mathrm{L})$ & Reference \\
\hline $\mathrm{CuO}$ NPs-CILE & $0.001-2.5$ & 0.5 & 19 \\
$\mathrm{Cu}_{2} \mathrm{O} / \mathrm{GN} / \mathrm{GCE}$ & $0.3-7.8$ & 20.8 & 34 \\
$\mathrm{rGO} / \mathrm{CNT} / \mathrm{AgNP} / \mathrm{GCE}$ & $0.01-10$ & 1.0 & 35 \\
$\mathrm{Co}_{3} \mathrm{NNW} / \mathrm{TM}$ & $0.002-28$ & 1.0 & 36 \\
$\mathrm{Cu}_{2} \mathrm{OMS}-\mathrm{rGO}$ & $0.005-2.775$ & 10.8 & 37 \\
$\mathrm{NiO} / \alpha-\mathrm{Fe}_{2} \mathrm{O}_{3}$ & $0.5-3$ & 50 & 38 \\
$\mathrm{GO} / \mathrm{Ag}$ nanocomposite & $0.1-11$ & 28 & 39 \\
$\mathrm{CB} / \mathrm{PI}-\mathrm{GCE}$ & $0.006-10$ & 1.0 & This work \\
\hline
\end{tabular}

NPs, nanoparticles. CILE, carbon ionic liquid electrode. GN, graphene nanosheets. rGO, reduced graphene. CNT, carbon nanotubes. AgNPs, Ag nanoparticles. GCE, glassy carbon electrode. $\mathrm{Co}_{3} \mathrm{NNW}$, cobalt nitride nanowire. TM, Ti mesh. GO, graphene.

\subsection{Reproducibility, repeatability, long-term stability, and interference}

The reproducibility of the CB/PI-GCE sensor was measured at a $\mathrm{H}_{2} \mathrm{O}_{2}$ concentration of 50 $\mu \mathrm{M}$ in $0.1 \mathrm{M} \mathrm{NaOH}$ aqueous solution, as shown in Fig. 5(C). From the result, the proposed sensor shows good operational stability during 40 measurements. The responses in 20 successive assays were examined and the relative standard deviation (RSD \%) was 5.5\%. Five different $\mathrm{CB} / \mathrm{PI}-\mathrm{GCE}$ electrodes were prepared independently and the RSD \% was 5.2\% [Fig. 6(A)]. The CB/PI-GCE [Fig. 6(B), blue] and CB-GCE [Fig. 6(B), yellow] sensors were stored in a dry state at room temperature when not in use. The current response almost disappeared after 1 month of storage for CB-GCE. On the other hand, the current response remained at $98 \%$ of the initial current over $30 \mathrm{~d}$ for $\mathrm{CB} / \mathrm{PI}-\mathrm{GCE}$, indicating good stability of the present electrode. The good stability is attributable to the excellent stability of the PI.

Selectivity is an important parameter for the nonenzymatic $\mathrm{H}_{2} \mathrm{O}_{2}$ sensor to ensure high accuracy. ${ }^{(40)}$ In order to evaluate the selectivity of the nonenzymatic sensor, the effect of some possible interfering substances was examined. The typical amperometric current on successive additions of $0.2 \mathrm{mM} \mathrm{H}_{2} \mathrm{O}_{2}$ and $0.2 \mathrm{mM}$ interference species (glucose, fructose, and sucrose) under stirring is shown in Fig. 5(D). The anti-interference ability is important in real aqueous solutions for the future practical applications of amperometric nonenzymatic sensors. As shown in Fig. 5(D), the response currents of interferents are negligible in comparison with the response of $\mathrm{H}_{2} \mathrm{O}_{2}$. The results are very valuable and encouraging for real sample determination.

\subsection{Application of modified electrode}

To understand the practical applicability of the CB/PI-GCE-based sensor for real sample measurement, the sensor was applied to determine the drinking water in our laboratory. The results are shown in Table 2. The CB/PI-GCE sensor shows good selectivity to $\mathrm{H}_{2} \mathrm{O}_{2}$, the RSD and recovery of which were less than 2.8 and $92.4-101.0 \%$, respectively. The results suggest that the sensor can be used to detect and measure the concentration of $\mathrm{H}_{2} \mathrm{O}_{2}$ in real samples. 

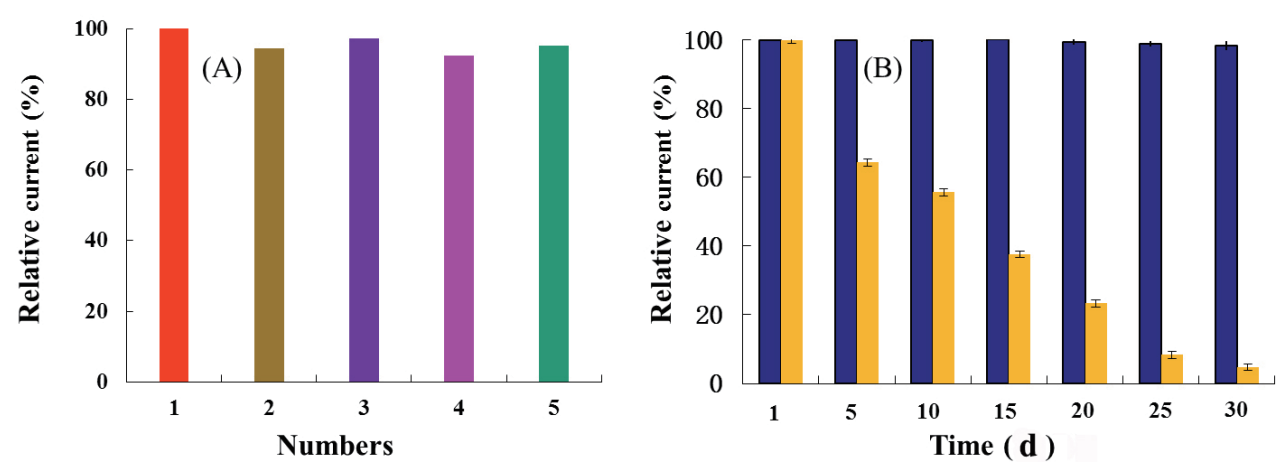

Fig. 6. (Color online) (A) Reproducibility of five parallel CB/PI-GCE sensors towards $0.2 \mathrm{mM} \mathrm{H}_{2} \mathrm{O}_{2}$. (B) Longterm stabilities of CB/PI-GCE (blue) and CB-GCE (yellow) sensors on the detection of $0.2 \mathrm{mM} \mathrm{H}_{2} \mathrm{O}_{2}$ (applied potential $+0.6 \mathrm{~V}$ vs $\mathrm{Ag} / \mathrm{AgCl}, 0.1 \mathrm{M} \mathrm{NaOH}$ aqueous solution).

Table 2

CB/PI-GCE sensor applied to drinking water.

\begin{tabular}{lccccc}
\hline Number & Detected $(\mu \mathrm{M})$ & Added $(\mu \mathrm{M})$ & Found $(\mu \mathrm{M})$ & RSD $(\%)$ & Recovery $(\%)$ \\
\hline 1 & Not found & 50 & 48.0 & 2.8 & 96.0 \\
2 & Not found & 100 & 101 & 1.9 & 101.0 \\
3 & Not found & 200 & 184.9 & 2.5 & 92.4 \\
\hline
\end{tabular}

\section{Conclusions}

Carbon-black-doped PI was used for electrode modification in the fabrication of a nonenzymatic $\mathrm{H}_{2} \mathrm{O}_{2}$ sensor. It was found that the proposed sensor exhibits good electrocatalytic activity for $\mathrm{H}_{2} \mathrm{O}_{2}$ detection. From this study, it is reasonable to use PI as the basic material to enhance the stability and lifetime of sensors. Because of its high stability, the PI-based sensor can be applied in extreme environments. Further studies will be focused on the practical usage of PI as electrochemical amperometric sensors for the determination of other chemical compounds. The combination with the enzyme is also promising for future application in biodevices such as biosensors and biofuel cells.

\section{Acknowledgments}

The authors gratefully acknowledge the financial support from the Natural Science Foundation of Liaoning Province (No. 20170540464), the Department of Education of Liaoning (No. 2017LNQN05), and the Foundation of University of Science and Technology, Liaoning (No. 2016RC12).

\section{References}

1 Z. F. Yao, X. Yang, F. Wu, W. L. Wu, and F. P. Wu: Microchim. Acta 183 (2016) 2799. https://doi.org/10.1007/s 00604-016-1924-2

2 C. L. Wang and A. Mulchandani: Anal. Chem. 67 (1996) 1109. https://doi.org/10.1021/ac00102a014

3 U. Pinkernell, S. Effkemann, and U. Karst: Anal. Chem. 69 (1997) 3623. https://doi.org/10.1021/ac9701750 
4 D. E. Achatz, R. J. Meier, L. H. Fishcher, and O. S. Wolfbeis: Angew. Chem. Int. Ed. 50 (2011) 260. https://doi. org/10.1002/anie.201004902

5 S. X. Xu, X. J. Qin, X. F. Zhang, and C. X. Zhang: Microchim. Acta 182 (2015) 1241. https://doi.org/10.1007/ s00604-014-1444-X

6 L. Tian, Y. J. Feng, Y. J. Qi, B. B. Wang, Y. R. Chen, and X. Y. Fu: Microchim. Acta 177 (2012) 39. https://doi. org/10.1007/s00604-011-0746-5

7 J. B. Jia, B. Q. Wang, A. G. Wu, G. J. Cheng, Z. Li, and S. J. Dong: Anal. Chem. 74 (2002) 2217. https://doi. org/10.1021/ac011116w

8 Y. Wang and Y. Hasebe: Sens. Actuators, B 155 (2011) 722. https://doi.org/10.1016/j.snb.2011.01.037

9 Y. Wang and Y. Hasebe: Anal. Sci. 27 (2011) 401. https://doi.org/10.2116/analsci.27.401

10 J. M. Huang, J. Zheng, and Q. Sheng: Microchim. Acta 173 (2011) 157. https://doi.org/10.1007/s00604-010$0529-4$

11 J. Xu, C. Liu, and Z. Wu: Microchim. Acta 172 (2011) 425. https://doi.org/10.1007/s00604-010-0515-x

12 L. Zhang: Biosens. Bioelectron. 23 (2008) 1610. https://doi.org/10.1016/j.bios.2008.01.022

13 S. Park, H. Boo, and T. D. Chung: Anal. Chim. Acta 556 (2006) 46. https://doi.org/10.1007/978-3-319-03002-9133

14 W. D. Lu, Y. J. Sun, H. C. Dai, P. J. Ni, S. Jiang, Y. L. Wang, Z. Li, and Z. Li: Sens. Actuators, B 231 (2016) 860. https://doi.org/10.1016/j.snb.2016.03.058

15 Z. Zhang, S. Q. Gu, Y. P. Ding, F. F. Zhang, and J. D. Jin: Microchim. Acta 180 (2013) 1043. https://doi. org/10.1007/s00604-013-1012-9

16 J. Y. Jin, W. Q. Wu, H. Min, H. M. Wu, S. F. Wang, Y. Ding, and S. J. Yang: Microchim. Acta 184 (2017) 1389. https://doi.org/10.1007/s00604-017-2105-7

17 H. Razmi and R. Mohammad-Rezaei: Microchim. Acta 171 (2010) 257. https://doi.org/10.1007/s00604-0100426-x

18 C. J. Zhao, X. Wu, P. W. Li, C. H. Zhao, and X. Z. Qian: Microchim. Acta 184 (2017) 2341. https://doi. org/10.1007/s00604-017-2229-9

19 J. F. Ping, S. P. Ru, K. Fan, J. Wu, and Y. B. Ying: Microchim. Acta 171 (2010) 117. https://doi.org/10.1007/ s00604-010-0420-3

20 S. D. Ravi, N. Uehera, and T. Kato: Anal. Bioanal. Chem. 374 (2002) 412. https://doi.org/10.1007/s00216-0021507-4

21 H. Wei, J. D. Xie, X. M. Jiang, T. Ye, A. P. Chang, and W. T. Wu: Macromolecules 47 (2014) 6067. https://doi. org/10.1021/ma5013368

22 K. Thenmozhi and N. S. Sriman: Anal. Bioanal. Chem. 387 (2007) 1075. https://doi.org/10.1007/s00216-0060992-2

23 J. Yang, M. Lin, M. S. Cho, and Y. K. Lee: Microchim. Acta 182 (2015) 1089. https://doi.org/10.1007/s00604014-1433-0

24 Y. Wang, K. J. Zhao, D. P. Tao, F. G. Zhai, H. B. Yang, and Z. Z. Zhang: RSC Adv. 8 (2018) 5013. https://doi. org/10.1039/C7RA13628E

25 W. Y. Chang, T. H. Fang, and Y. C. Lin: Appl. Phys. A 92 (2008) 693. https://doi.org/10.1007/s00339-0084623-y

26 W. Jang, J. Seo, C. Lee, S. H. Peak, and H. Han: J. Appl. Polym. Sci. 113 (2009) 976. https://doi.org/10.1002/ app. 29558

27 W. B. Jang, H. S. Lee, S. Lee, S. Choi, D. Shin, and H. Han: Mater. Chem. Phys. 104 (2007) 342. https://doi. org/10.1016/j.matchemphys.2007.03.025

28 S. H. Hsiao and Y. J. Chen: Eur. Polym. J. 38 (2002) 815. https://doi.org/10.1016/S0014-3057(01)00229-4

29 Y. Wang and Y. Hasebe: Materials 7 (2014) 1142. https://doi.org/10.3390/ma7021142

30 H. Y. Song, C. H. Ma, L. Y. You, Z. Y. Cheng, X. H. Zhang, B. S. Yin, Y. N. Ni, and K. Q. Zhang: Microchim. Acta 182 (2015) 1543. https://doi.org/10.1007/s00604-015-1485-9

31 A. J. Kinloeh: Adhesion and Adhesive Science and Technology (Champman and Hall, New York, 1990) p. 39.

32 L. Mei, P. C. Zhang, J. Y. Chen, D. D. Chen, Y. Quan, N. Gu, G. H Zhang, and R. J. Cui: Microchim. Acta 183 (2016) 1359. https://doi.org/10.1007/s00604-016-1764-0

33 S. X. Xu, X. J Qin, X. F. Zhang, and C. X. Zhang: Microchim. Acta 182 (2015) 1241. https://doi.org/10.1007/ s00604-014-1444-X

34 E. T. D. Kumar and V. Ganesh: Appl. Biochem. Biotechnol. 174 (2014) 1043. https://doi.org/10.1007/s12010014-0999-7

35 Y, Zhang, Z. Y. Wang, Y. Ji, S. Liu, and T. Zhang: RSC Adv. 5 (2015) 39037. https://doi.org/10.1039/ C5RA04246A 
36 F. Y. Xie, X. Q. Cao, F. L. Qu, A. M. Asiri, and X. P. Su: Sens. Actuators, B 255 (2018) 1254. https://doi. org/10.1016/j.snb.2017.08.098

37 J. W. Ding, W. Sun, G. Wei, and Z. Q. Su: RSC Adv. 5 (2015) 35338. https://doi.org/10.1039/c5ra00884k

38 D. S. Achari, C. Santhosh, R. Deivasegamani, R. Nivetha, A. Bhatnagar, S. K. Jeong, and A. N. Grace: Microchim. Acta 184 (2017) 3223. https://doi.org/10.1007/s00604-017-2335-8

39 F. Wang, W. C. Gong, L. L. Wang, and Z. L. Chen: Microchim. Acta 182 (2015) 1949. https://doi.org/10.1007/ s00604-015-1535-3

40 L. Y. Chen, T. Fujita, Y. Ding, and M. W. Chen: Adv. Funct. Mater. 20 (2010) 2279. https://doi.org/10.1002/ adfm. 201000326

\section{About the Authors}

Yue Wang received her B.S. and M.S. degrees from the University of Science and Technology Liaoning, China, in 2002 and 2006, respectively, and her Ph.D. degree from Saitama Institute of Technology, Japan, in 2011. From 2006 to 2011, she was a lecturer at the University of Science and Technology Liaoning, China. Since 2012, she has been an associate professor at the University of Science and Technology Liaoning, China. Her research interests are in flexible materials, biosensors, and electrochemical sensors. (wangyue@ustl.edu.cn)

Lin Chen received her B.S. and M.S. degrees from Shenyang University of Chemical Technology, China, in 2007 and 2010, respectively. She is a Ph.D student in the University of Science and Technology Liaoning. Since 2010, she has been a lecturer at Yingkou Institute of Technology. (guanzhu84@163.com)

Yan Zhang received his B.S. degree from the University of Science and Technology Liaoning, China, in 2018. He is a graduate student in the University of Science and Technology Liaoning, China. His research interests are in electrochemical sensors and flexible materials. (1564224135@163.com)

Qingnan Wang is an undergraduate student in the University of Science and Technology Liaoning, China. Her research interests are in electrochemical sensors and flexible materials. (2967936599@qq.com)

Ruidan Ma is an undergraduate student in the University of Science and Technology Liaoning, China. Her research interests are in electrochemical sensors and flexible materials.

(554697213@qq.com)

Yasushi Hasebe received his B.S. degree from Tohoku University, Japan, in 1987 and his M.S. and Ph.D. degrees from Tohoku University, Japan, in 1989 and 1991, respectively. From 1992 to 2008, he was a lecturer and an associate professor at Saitama Institute of Technology, Japan. Since 2009, he has been a professor at Saitama Institute of Technology. His research interests are in electrochemical biosensors and enzyme-based biofuel cells. (hasebe@sit.ac.jp) 
Zhiqiang Zhang received his B.S. degree from Nankai University, China, in 1985, and his M.S. and Ph.D. degrees from the University of Science and Technology Liaoning and Dalian University of Technology, China, in 1990 and 2009, respectively. From 1985 to 2000, he was a lecturer and an associate professor at the University of Science and Technology Liaoning, China. Since 2000, he has been a professor at the University of Science and Technology Liaoning, China. His research interests are in organic synthesis, catalysis, and sensors.

(zhangzhiqiang@ustl.edu.cn)

Zhizhi Hu received his B.S. degree from Dalian University of Technology, China, in 1983. He received his M.S. and Ph.D. degrees from Okayama University, Japan, in 1994 and 2000, respectively. Since 2000, he has been a professor at the University of Science and Technology Liaoning, China. His research interests are in polymers, organic synthesis, and sensors. (huzhizhi@163.com)

\section{Appendix}
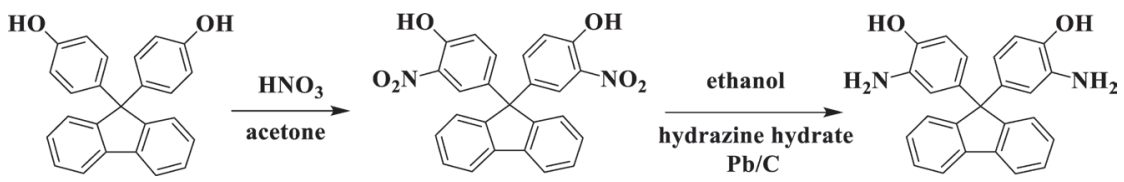

Fig. A1. Synthesis procedures of dinitro compound (BNHF) and diamine monomer (BAHF).<smiles>Nc1cc(C2(c3ccc(O)c(O)c3)c3ccccc3-c3ccccc32)ccc1O</smiles>

$+\mathbf{n}$<smiles>CC(C)(c1ccc2c(c1)C(=O)OC2=O)c1ccc2c(c1)C(=O)OC2=O</smiles>

Poly(amic acid)

$\mathbf{N}_{2}$<smiles>CC(C)(C)c1ccc(C2(c3ccc(O)c(N=CC(=O)c4cc(C(F)(F)F)ccc4C(=O)O)c3)c3ccccc3-c3ccccc32)cc1C(=O)O</smiles>

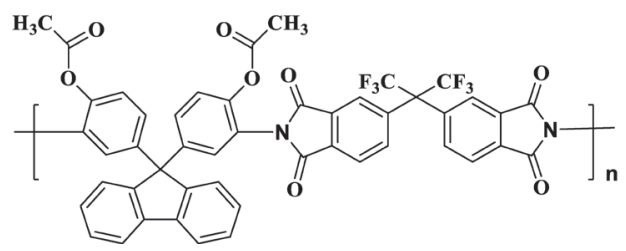

Fig. A2. Synthesis procedures of PI powder. 


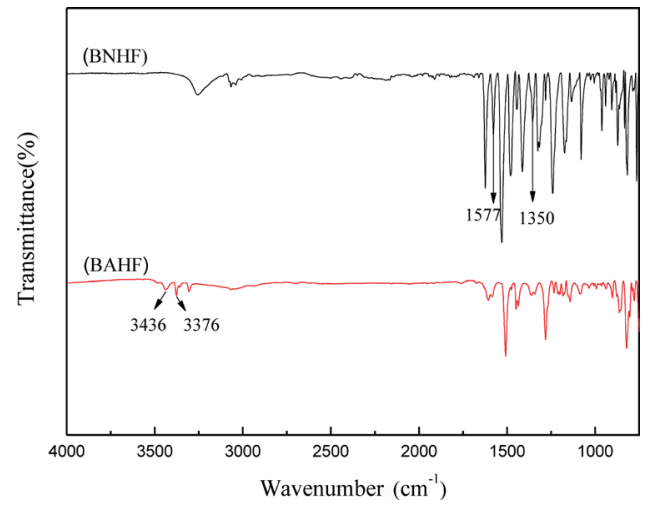

Fig. A3. (Color online) FT-IR spectra of dinitro compound (BNHF) and diamine monomer (BAHF).

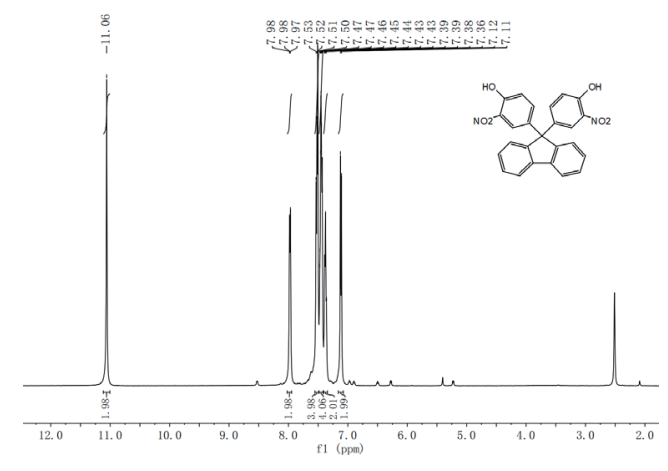

Fig. A4. ${ }^{1} \mathrm{H}-\mathrm{NMR}$ spectrum of dinitro compound (BNHF).

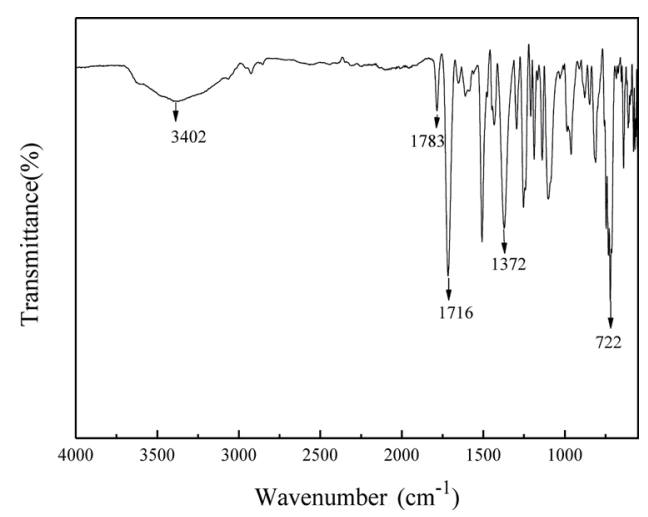

Fig. A6. FT-IR spectra of PI.

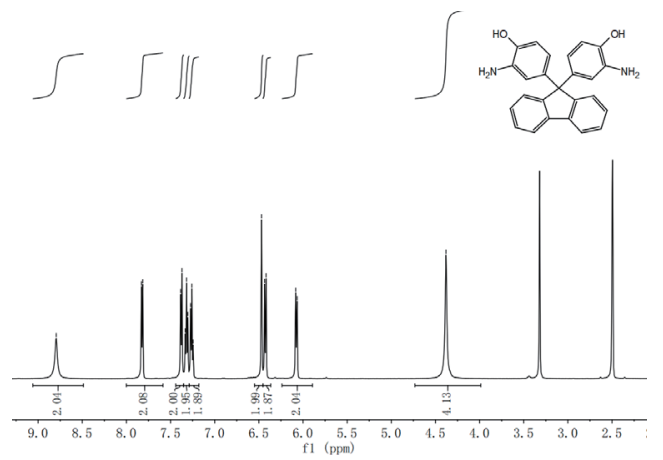

Fig. A5. ${ }^{1} \mathrm{H}-\mathrm{NMR}$ spectrum of diamine monomer (BAHF).

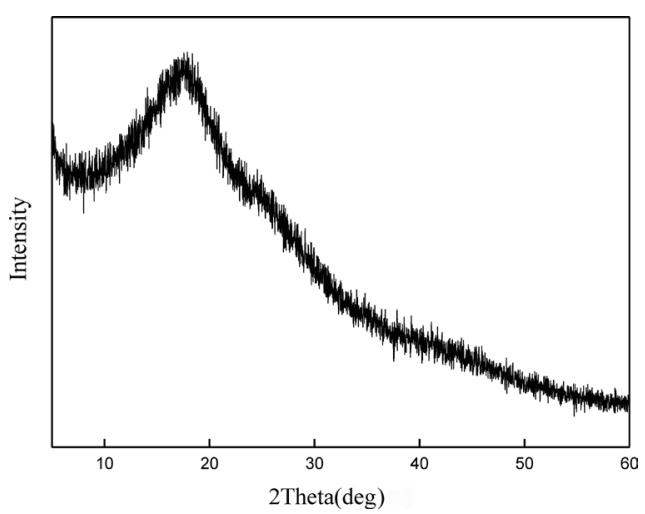

Fig. A7. XRD patterns of PI. 